\title{
Building Evacuate Module for Urban Underground Passages: Subway Station in Turkey
}

\author{
İlker Erkan, Hasan Hastemoglu \\ Architecture Faculty, Suleyman Demirel University, Isparta, Turkey \\ Email: ilkererkan@sdu.edu.tr, hasanhastemoglu@sdu.edu.tr
}

Received 16 October 2014; revised 8 November 2014; accepted 29 November 2014

Copyright (C) 2015 by authors and Scientific Research Publishing Inc.

This work is licensed under the Creative Commons Attribution International License (CC BY).

http://creativecommons.org/licenses/by/4.0/

(c) () Open Access

\begin{abstract}
The primary goal of crowd evacuation in urban underground passages or subways is to evacuate as many evacuees as possible to safe areas in the shortest time when emergency events occur. This paper chooses the underground passages of one metro in Istanbul, Turkey as research object, and uses a study method which combines by sites investigation, field test and computer simulation of the creating new software. It is called Building Evacuate Module software. We present a depth analysis of the related factors which include the number and width of passage, channelization setting and the number of pedestrians with the evacuation time. And the influential effect of public opinion is explained by using big data technology. In addition, pedestrians evacuation condition are recorded in three evacuation period, the morning peak, common and evening peak by the observation and statistic obtained with video, and build the model to simulate the change of evacuation time with pedestrians. So it reveals when the number of pedestrians reaches to more than 200, evacuation time increases significantly and the field experiment and simulation condition are consistent basically.
\end{abstract}

\section{Keywords}

Transport Planning, Building Evacuate Module, Crowd Evacuation, Metro Station

\section{Introduction}

At present, the crowd evacuation of underground passages has become an indispensable link in urban emergency evacuation of Turkey, but studies in this subject are not enough. However, the study of the aspect is not so much, of which the relevant theoretical basis is still relatively weak, even is very difficult [1] [2]. Therefore, the 
impact study on the large-scale crowd evacuation when there's an emergency event in urban underground passages, so as to improve the ability of the crowd evacuation, has become a key subject that can make a farreaching implication on the urban safety and social stability [2] [3].

Crowd management, control and evacuation are very new method for Turkey. Computer simulation technology developed overseas is commonly applied in working out safety management scheme [4] [5]. These simulations can be used to analyze the evacuation of buildings, subways, metros, stadiums and traffic networks and in the process of planning, simulation model provides the assessment network clearance time or detects bottleneck problems for emergency evacuation [5]. When researchers pass through the streets safely by underground passages, studies show that pedestrians have subjective conditions worse than objective conditions [6]. Capote, et al. [7] present a real-time model integrated in a Decision Support System for emergency management in road tunnel. The main difference is that the proposed model can provide results faster than real-time (less than $5 \mathrm{~s}$ ) while the run time of the other models is really higher. A novel approach is to represent space, which called the "Hybrid Spatial Discretisation”, in which all three spatial representations can be utilized to represent the physical space of the geometry within single integrated software [8]. To test the predictive capabilities of different evacuation modeling approaches to simulate tunnel fire evacuations, the study is based on the a priori modeling vs. a posteriori modeling of a set of tunnel evacuation experiments performed in a tunnel in Stockholm, Sweden [9]. Without crowding within the aisle, it would reduce the evacuation time by optimal design for the width of the entrance, opening exits and layout of escaping passages [10].

Therefore, how to calculate the ability of emergency evacuation accurately in underground passages or subway tunnels and to analyze its bottleneck are the basis of improving the efficiency of emergency evacuation and preventing crowd casualties in accidents. And they are also taking the important part in planning, designing and organizing passengers flows for underground passages or subway system.

\section{Analysis of Impact Factors}

It was clear from the results of crowd evacuation cases of underground passages or subway station, evacuation time has great relationship with factors of the "number of passage”, “width”, “canalization setting” and the "number of pedestrians”. In addition, the influential effect of public opinion is also significant after emergency event.

\subsection{The Number of Passage Exit}

The number of exit is an important indicator which can influence evacuation of people. In this case, we assume a total of 10,000 people are evacuated, in the area of 10,000 square meter, we set the exit width to 3 meter and the number of the exit is respectively 4, 6, 8 and 10, and with a velocity of $1.2 \mathrm{~m} / \mathrm{s}$. The scenario of evacuation simulation is shown in Figure 1.

Figure 2 shows the increase of the number of evacuating exits directly improves the efficiency of the evacuation.

When there're 4 evacuating exits, evacuation time is $798 \mathrm{~s}$, however, when the number of evacuating exits increases to eight, evacuation time is $388 \mathrm{~s}$. This means that when the number of evacuating exit multiplies, evacuation efficiency doesn't increase in equal proportion. The decline of the number of pedestrian out of each exit directly increases the degree of order of pedestrian evacuation. However, when the number of exits increases to a certain amount, the efficiency of evacuation cannot be improved anymore. Therefore, the number of exits of the building facilities should be set rationally according to the maximum capacity of venues.

\subsection{The Width of Passages Exit}

The effective width of the passage is an important factor which can influence evacuation ability of the pedestrian crossing [11] [12]. According to Code of Design on Building Fire Protection and Prevention (GB50016-2006), the width of safety exit is obtained from the expression in Equation 1.

$$
\mathrm{W}=\mathrm{S} \cdot \mathrm{D} \cdot \mathrm{E}
$$

where $\mathrm{W}$ is calculative width of the safety exit $(\mathrm{m}), \mathrm{S}$ is the area of Business hall $\left(\mathrm{m}^{2}\right)$, $\mathrm{D}$ is the person density of Business hall (person/ $\mathrm{m}^{2}$ ), E is the safety exit width index (m/100 person).

The model is established that there's a total of 10,000 people are evacuated and four exits, which respectively are 3, 6, 8 and 10 meters in this case and with a velocity of $1.2 \mathrm{~m} / \mathrm{s}$. 


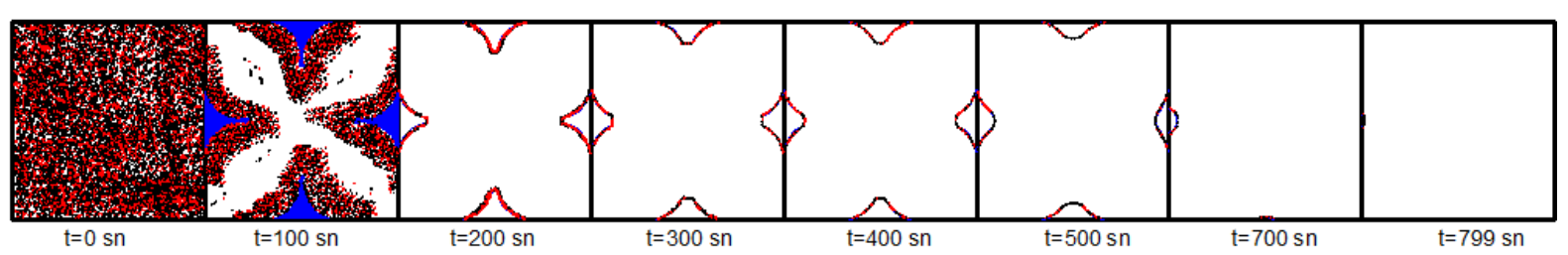

Figure 1. Simulation scenario of four exit gate.

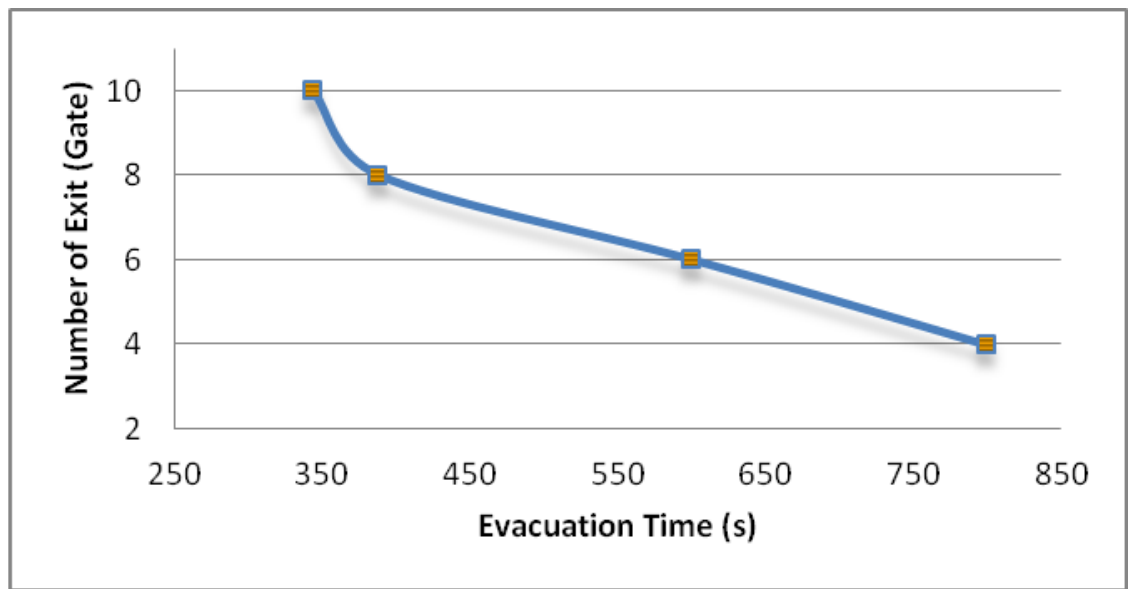

Figure 2. Number of exit-evacuation time.

Figure 3 shows that the increase of the evacuation exit width directly improves the efficiency of the evacuation.

When exits width is $3 \mathrm{~m}$, evacuation time is $798 \mathrm{~s}$, however, when the width increases to $6 \mathrm{~m}$, evacuation time is $396 \mathrm{~s}$. This means that when the width of evacuation exit multiplies, evacuation time doesn't decrease in equal proportion, but need more time. Therefore, the exit width of the building facilities should be set rationally according to the need of venues.

\subsection{Passages Canalization Setting}

Evacuation speed and the interference among pedestrians can be influenced by the width and the number of evacuating exits; in addition, the reasonable passage canalization set also can increase pedestrians' evacuation efficiency. Stimulating a situation that the evacuation door width is $1 \mathrm{~m}$, and the number of evacuation is 100 people, and with a velocity of $1.2 \mathrm{~m} / \mathrm{s}$. We set up four kinds of circumstances, in which pedestrian evacuate respectively on their own, one passage canalization being set, two passage canalization being set, and three passage canalization being set Figure 4. shows that when the emergency evacuation happen, setting effective channelized diversion objects at the entrances and exits, can reduce the evacuation conflict among pedestrians and also can increase the speed and evacuation order, in order to improve the efficiency and safety.

When too many channelized objects are set up in evacuating exits, it will go too far and the evacuation efficiency will be reduced.

\subsection{The Number of Pedestrians}

The number of pedestrians is also an important factor. In this case, we assume 50, 100, 150, 200, 250 , 300 people separately are evacuated at $1.2 \mathrm{~m} / \mathrm{s}$, across the underground passage with length of 20 meter and the width of 2 meter. And the scenario of evacuation simulation is shown in Figure 5 at Building Evacuate Module (BEM).

The relation of number of pedestrians and evacuation time in Figure 6.

Figure 6 shows that the evacuation time is rising with the number of pedestrians increasing. However, the trend graph indicates that the value of evacuation time is not increasing in proportion to the number of pedestrians. The more increase of the demand of the number of evacuated pedestrians, and the higher congestion in 


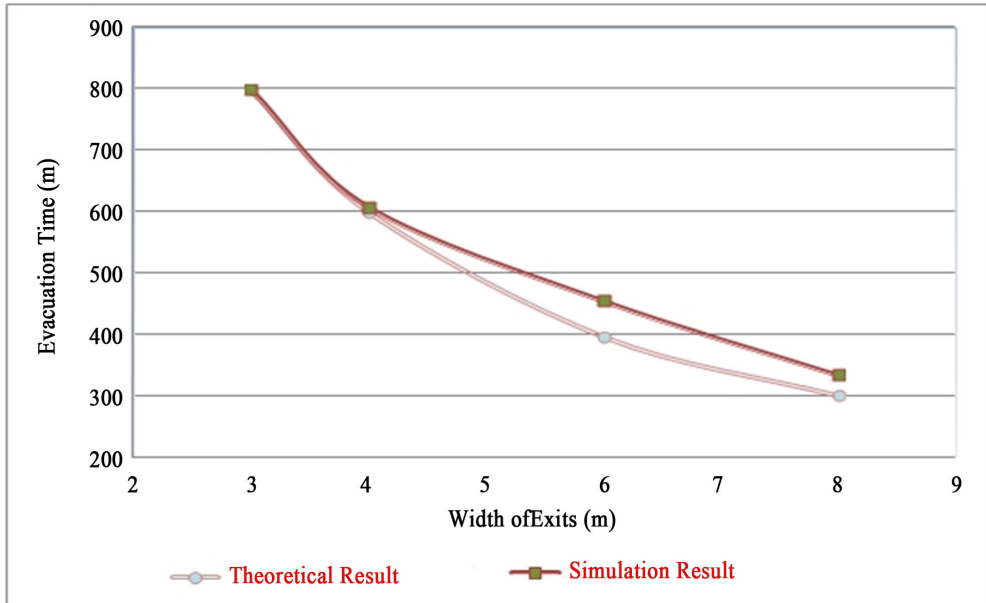

Figure 3. Relation width of exits and evacuation time.

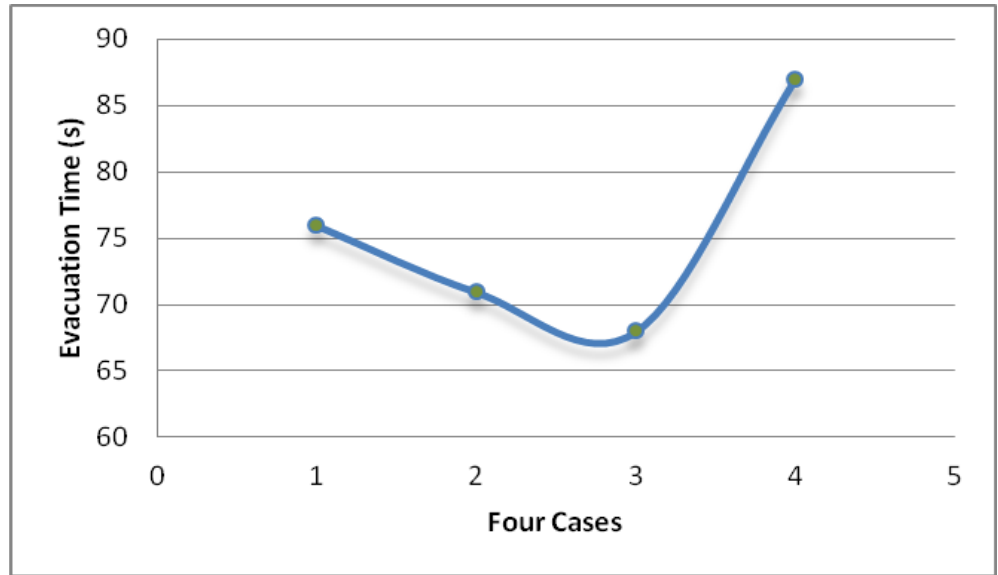

Figure 4. The four kinds of passages canalization setting and evacuation time.

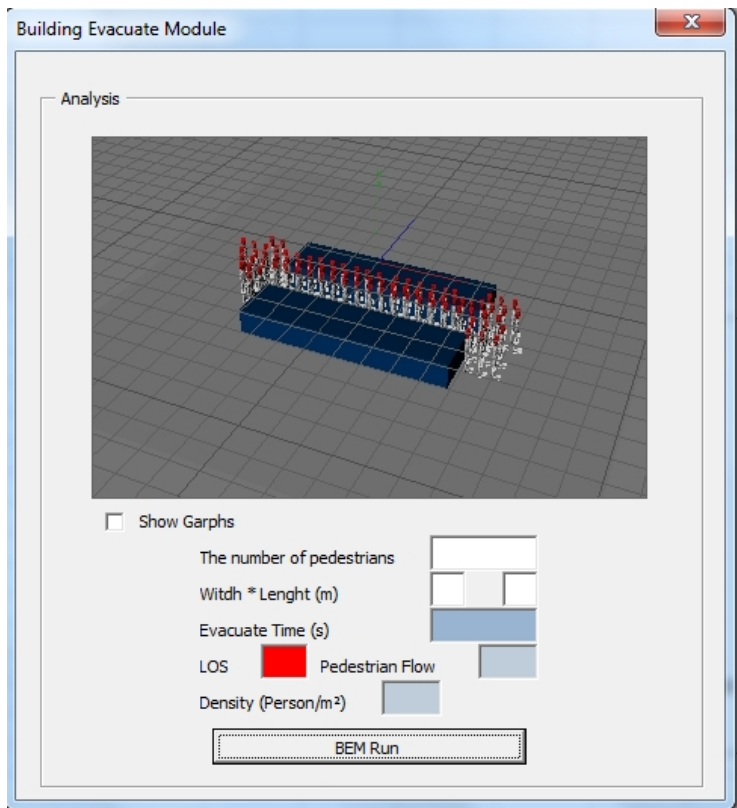

Figure 5. Interface of BEM. 


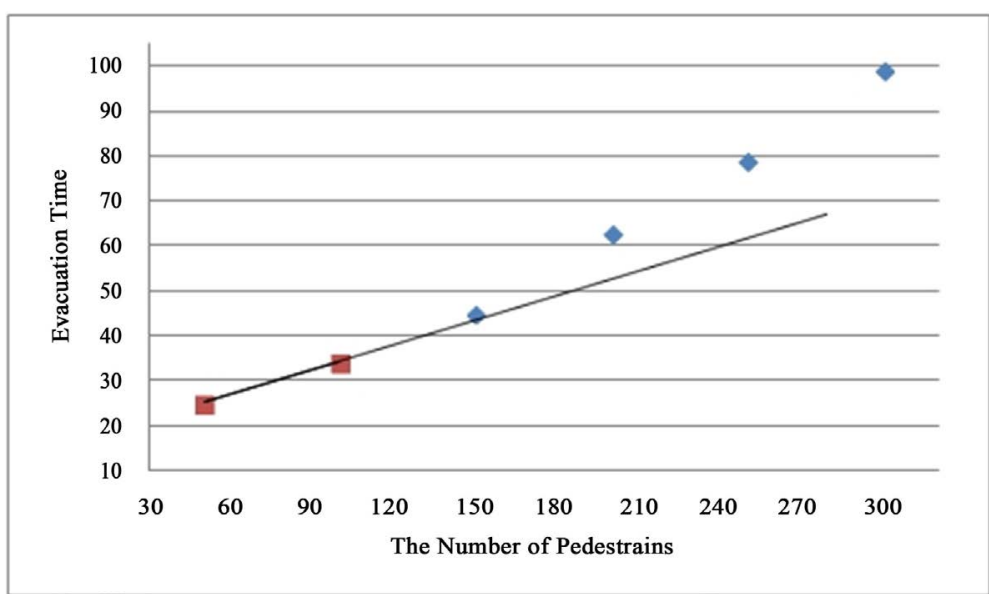

Figure 6. The relation of number of pedestrians and evacuation time.

the passage, results in a decline in the efficiency of the pedestrian evacuation, especially when the number of pedestrians gets reach to more than 200, evacuation time increases significantly. Besides, the impaired disabled are also led to a decline of the evacuation efficiency [13]. So the related management departments should strengthen control of the number of pedestrians in passages in order to reduce the accident interference in the process of evacuation.

\subsection{Effect of Public Opinion}

Emergency monitoring in underground passage or subway refer to that of the related network public opinion, especially when group emergency incidents occur. It's difficult for the department of administration to make judgments and decisions of the information because of so many changing factors of emergencies, complex internal relationship, unpredictable developing trend and complicated relevant information. Incidents of this kind have intense abruptness, strong social influence and short think time for policy makers and the consequences will be serious if you can't get the accurate information and make judgments in good time. However, collection, sorting and discrimination of all the information can't be handled leisurely for policy makers under great pressure, some valuable information may be omitted or ignored, so that the decision-making of treatment is misleading. New opportunities and prospects for emergency management in urban area have been brought in big data era. The bigger the scale of data about city underground passage or subway station, the more difficult to handle, but the better value may be got from the data mining. In crisis situations, department of emergency management can understand the needs, demands and feelings of public by collecting and analyzing public opinion using big data technology, they can also monitor hot issues and track the source of all information with text messages, microblog, wechat and search engine. Therefore, it's an important influence factor in evacuation of underground passage or subway station in urban area for public opinion.

\section{Service Level}

The characteristics of pedestrian traffic and the factors of physiological and psychological in Turkey have a greater difference. Therefore, with the research results from abroad and the pedestrian's characteristics and investigation, classification indexes of service level for pedestrians proceeding are brought forward as shown in Table 1.

Under general condition, pedestrian density of the crowded underground passages should be controlled according to the corresponding value of $\mathrm{C}$ level of service. While pedestrian density of the peak can reach to D level of service in a short time, admissible to $\mathrm{E}$ level at moment.

\section{Evacuation Model}

\subsection{Field Test}

One underground passage of subway station in Turkey as study object in the paper, has the unidirectional width 
of 2 meters.

In the field test, the number of evacuees each one minute of an interval is recorded in three evacuation period, the morning peak, common and evening peak by the observation and statistic obtained with video, as shown in Table 2.

From Figure7 it is clear that the number of pedestrians is within 90 in the common period (note: the width is 2meter), so pedestrian density range of the underground passage can be controlled, service level between $B$ and C by obtained from Table 1 .

However, in the evacuation period in morning peak and evening peak, the number of pedestrians of the underground passage is more than 120, and it is relatively crowed, the service level has reached the E, and even up to $\mathrm{F}$ in some time.

From above, the E level of service is admissible at moment. However, the underground passage is overcrowding with a long time, so the department of metro or transport should be caused take seriously, to take measures so that the traffic jams stampede.

Table 1. The recommends table of the standard for pedestrians service level in Turkey for subway and underground.

\begin{tabular}{|c|c|c|c|c|}
\hline Service Level & Density (person/m²) & Per Capita Space (m²/person) & $\begin{array}{l}\text { Pedestrian Flow } \\
\text { (Person/min·m) }\end{array}$ & Velocity $(\mathbf{m} / \mathbf{s})$ \\
\hline $\mathbf{A}$ & $<0.2$ & $>5$ & 25 & $1.1-1.5$ \\
\hline B & $0.2-0.8$ & $3.5-5$ & 32 & $0.9-1.1$ \\
\hline C & $0.28-0.5$ & $2-3.5$ & 45 & $0.8-0.9$ \\
\hline D & $0.5-0.83$ & $1.2-2$ & 62 & $0.7-0.8$ \\
\hline $\mathbf{E}$ & $0.83-2.5$ & $0.4-1.2$ & 90 & $0.5-.0 .7$ \\
\hline $\mathbf{F}$ & $>2.5$ & $<0.4$ & - & $<0.5$ \\
\hline
\end{tabular}

Table 2. The number of evacuees in the three periods (Morning peak, common and evening peak).

\begin{tabular}{|c|c|c|c|c|c|}
\hline \multirow[b]{2}{*}{ EVACUATION PERIOD } & \multicolumn{5}{|c|}{ PEOPLE } \\
\hline & $\begin{array}{c}\text { First } \\
1 \text { minute }\end{array}$ & $\begin{array}{l}\text { Second } \\
1 \text { minute }\end{array}$ & $\begin{array}{l}\text { Third } \\
1 \text { minute }\end{array}$ & $\begin{array}{l}\text { Fourth } \\
1 \text { minute }\end{array}$ & $\begin{array}{l}\text { Fifth } \\
1 \text { minute }\end{array}$ \\
\hline Morning Peak & 132 & 168 & 184 & 153 & 128 \\
\hline Common & 86 & 90 & 66 & 54 & 89 \\
\hline Evening Peak & 128 & 144 & 136 & 166 & 153 \\
\hline
\end{tabular}

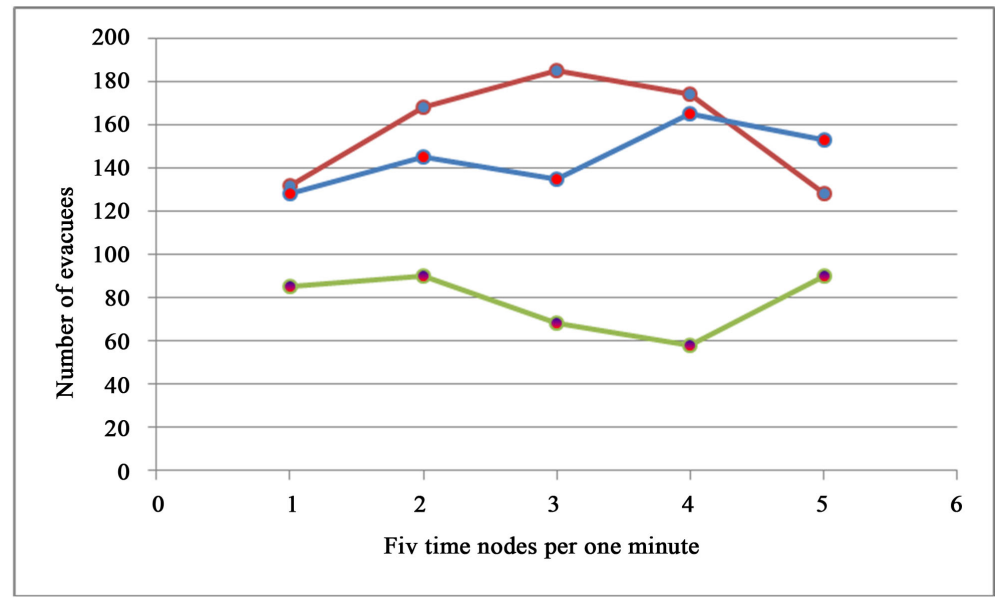

Figure 7. The underground passage of subway station in Turkey. 
From above, the E level of service is admissible at moment. However, the underground passage is overcrowded in a long time, so the department of metro or transport should take seriously attention, to take measures to prevent the traffic jams and even stampede accidents or other emergency events caused by it.

\subsection{Simulation}

The model is built according to the same parameters with the underground passage, and with a velocity of 1.2 $\mathrm{m} / \mathrm{s}$, to conduct the walking velocity and the evacuation simulations as shown in Figure 8 and Figure 9 by setting 10 groups with different intensity of pedestrian flow from 30 to 300 pedestrians are passing the underground passage in one minute.

Figure 8 and Figure 9 show that a decline in the walking velocity of the pedestrian evacuation is brought about, along with the increase of the demand of pedestrian evacuation and the degree of crowding of the passage. The number of pedestrian evacuation increases with the enlarging of demand, however, passage evacuation capacity reaches the limit to certain intensity; the number of evacuation does not continue to increase accordingly. And the simulation results are consistent basically with field test.

Therefore, pedestrian passages should be evaluated when evacuation passageways are set up in combination with evacuation flow intensity ,in the meantime, we suggested considering not only the limit of the passage evacuation capacity ,but also the suitable evacuation walking speed and the time crossing the evacuation passageway, in order to reduce interference of the emergency in the process of evacuation.

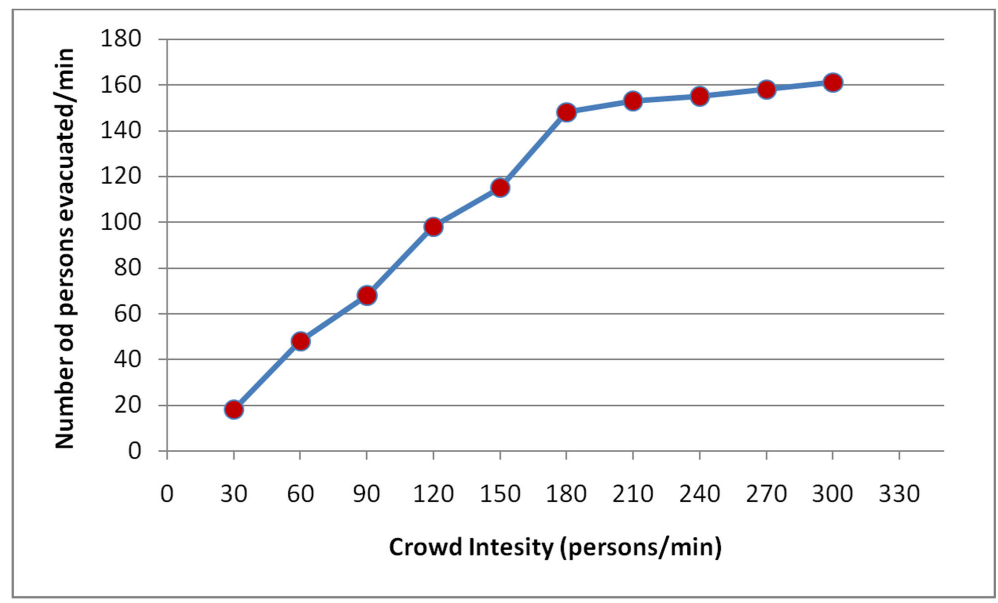

Figure 8. Relation of crowd intensity and the number of pedestrians per minute.

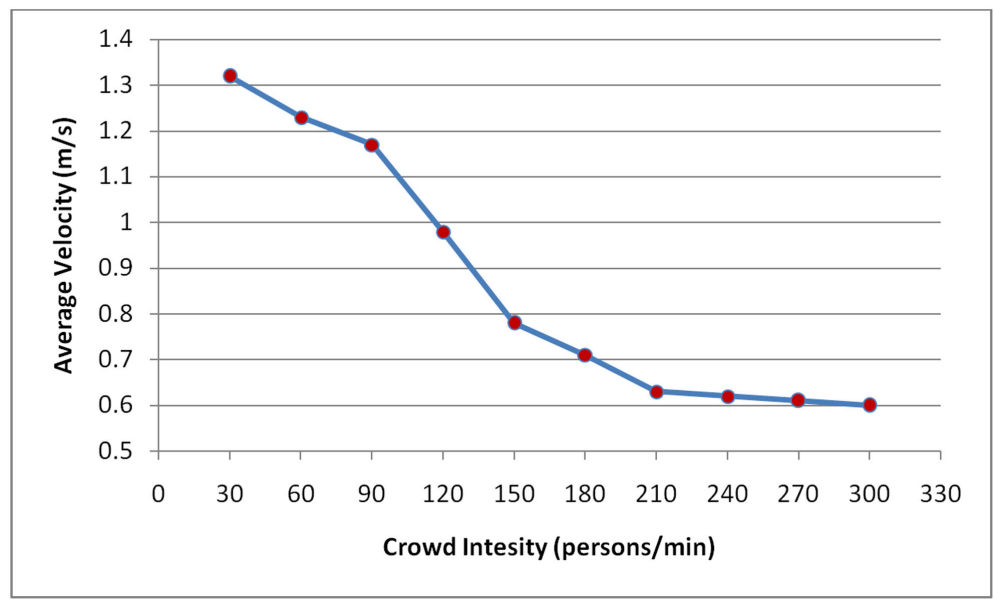

Figure 9. Relation of crowd intensity and average walking velocity. 


\section{Conclusion}

In this paper we have presented a comprehensive study approach and considered many factors to make a plan for pedestrian evacuation in urban underground passages or metros in Turkey. The number and width of passages for pedestrians are two important parameters related to affect the evacuation capability. So building facilities should be set rationally according to the maximum capacity of venues. The demand for quantity of evacuees has a prodigious impact on the evacuation efficiency. So effective analysis of the relationship between quantity of evacuees and evacuation speed is conducive to provide a reference basis for emergency evacuation in a place which has high-density public, and also take examples for the safeguard mechanisms in big public buildings. The influence factors of pedestrian speed are so many, which also have the large range. According to the results of domestic and international research relevant, it shows that due to the differences of pedestrian age, physiology (height, weight, etc.) and investigating locations, the pedestrian speed is usually from $1.0 \mathrm{~m} / \mathrm{s}$ to $1.4 \mathrm{~m} / \mathrm{s}$. It is extremely important for improved mechanism of public opinion monitoring, timely and effective collection and analysis of public opinion information, and a comprehensive grasp of various kinds of information closely related to the event in emergency events.

\section{Acknowledgements}

The authors would like to acknowledge the Suleyman Demirel University Scientific Research Project, which collectively funded this project.

\section{References}

[1] Jiang, C.S., Deng, Y.F., Hu, C., Ding, H. and Chow, W.K. (2009) Crowding in Platform Staircases of a Subway Station in China during Rush Hours. Safety Science, 47, 931-938. http://dx.doi.org/10.1016/j.ssci.2008.10.003

[2] Jiang, C.S. and Ling, Y. (2009) Numerical Simulation of Emergency Evacuation of a Subway Station. Architectural Science Review, 52, 183-193. http://dx.doi.org/10.3763/asre.2008.0047

[3] Chen, Y.Z., Cai, S.J. and Deng, Y.F. (2012) Simulation Study on Main Affect Factors to the Evacuation Corridor. Applied Mechanics and Materials, 170-173, 3533-3538. http://dx.doi.org/10.4028/www.scientific.net/AMM.170-173.3533

[4] Jiang, C.S., Yuan, F. and Chow, W.K. (2010) Effect of Varying Two Key Parameters in Simulating Evacuation for Subway Stations in China. Safety Science, 48, 445-451. http://dx.doi.org/10.1016/j.ssci.2009.12.004

[5] Shi, C., Zhong, M., Nong, X., He, L., Shi, J. and Feng, G. (2012) Modeling and Safety Strategy of Passenger Evacuation in a Metro Station in China. Safety Science, 50, 1319-1332. http://dx.doi.org/10.1016/j.ssci.2010.07.017

[6] Mahdavinejad, M., Hosseini, A. and Alavibelmana, M. (2012) Enhancement HSE Factors in Pedestrian Underpass regarding to Chemical Hazards, Mashhad, Iran. Social and Behavioral Sciences, 51, 10-14. http://dx.doi.org/10.1016/j.sbspro.2012.08.110

[7] Capote, J., Alvear, D., Abreu, O., Cuesta, A. and Alonso, V. (2012) A Real-Time Stochastic Evacuation Model for Road Tunnels. Safety Science, 52, 73-80. http://dx.doi.org/10.1016/j.ssci.2012.02.006

[8] Chooramun, N., Lawrence, P.J. and Galea, E.R. (2012) An Agent Based Evacuation Model Utilising Hybrid Space Discretisation. Safety Science, 50, 1685-1694. http://dx.doi.org/10.1016/j.ssci.2011.12.022

[9] Ronchi, E. (2013) Testing the Predictive Capabilities of Evacuation Models for Tunnel Fire Safety Analysis. Safety Science, 59, 141-153. http://dx.doi.org/10.1016/j.ssci.2013.05.008

[10] Chen, Y.Z., Yang, R. and Liu, Y. (2014) Strategy Study on Mass Evacuation with LBS Information. Web-Age Information Management, 141-150.

[11] Bles, W., Nooy, S. and Boer, L.C. (2001) Influence of Ship Listing and Ship Motion on Walking Speed. Proceedings of First Conference on Pedestrian and Evacuation Dynamics, Duisburg, 4-6 April 2001, 437-452.

[12] Watts, J.M. (1987) Computer Models for Evacuation Analysis. Fire Safety Journal, 12, 237-245. http://dx.doi.org/10.1016/0379-7112(87)90008-7

[13] Jiang, C.S., Zheng, S.Z., Yuan, F., Jia, H.J., Zhan, Z.N. and Wang, J.J. (2012) Experimental Assessment on the Moving Capabilities of Mobility-Impaired Disabled. Safety Science, 50, 974-985. http://dx.doi.org/10.1016/j.ssci.2011.12.023 
Scientific Research Publishing (SCIRP) is one of the largest Open Access journal publishers. It is currently publishing more than 200 open access, online, peer-reviewed journals covering a wide range of academic disciplines. SCIRP serves the worldwide academic communities and contributes to the progress and application of science with its publication.

Other selected journals from SCIRP are listed as below. Submit your manuscript to us via either submit@scirp.org or Online Submission Portal.
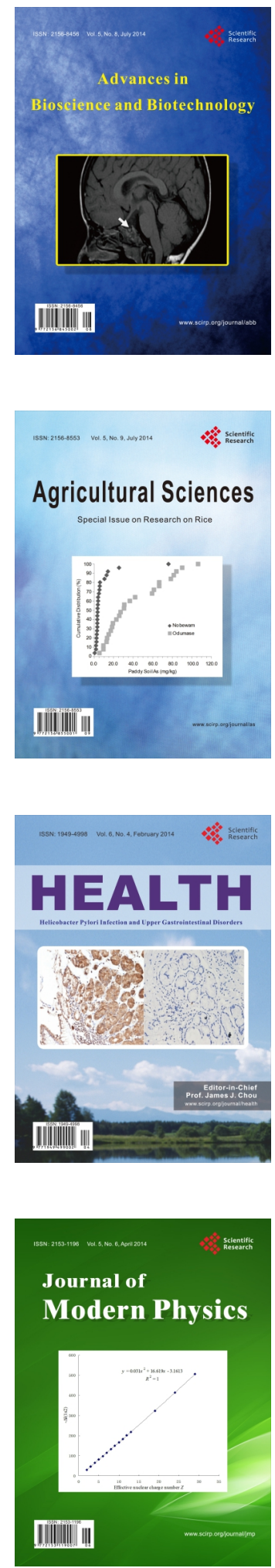
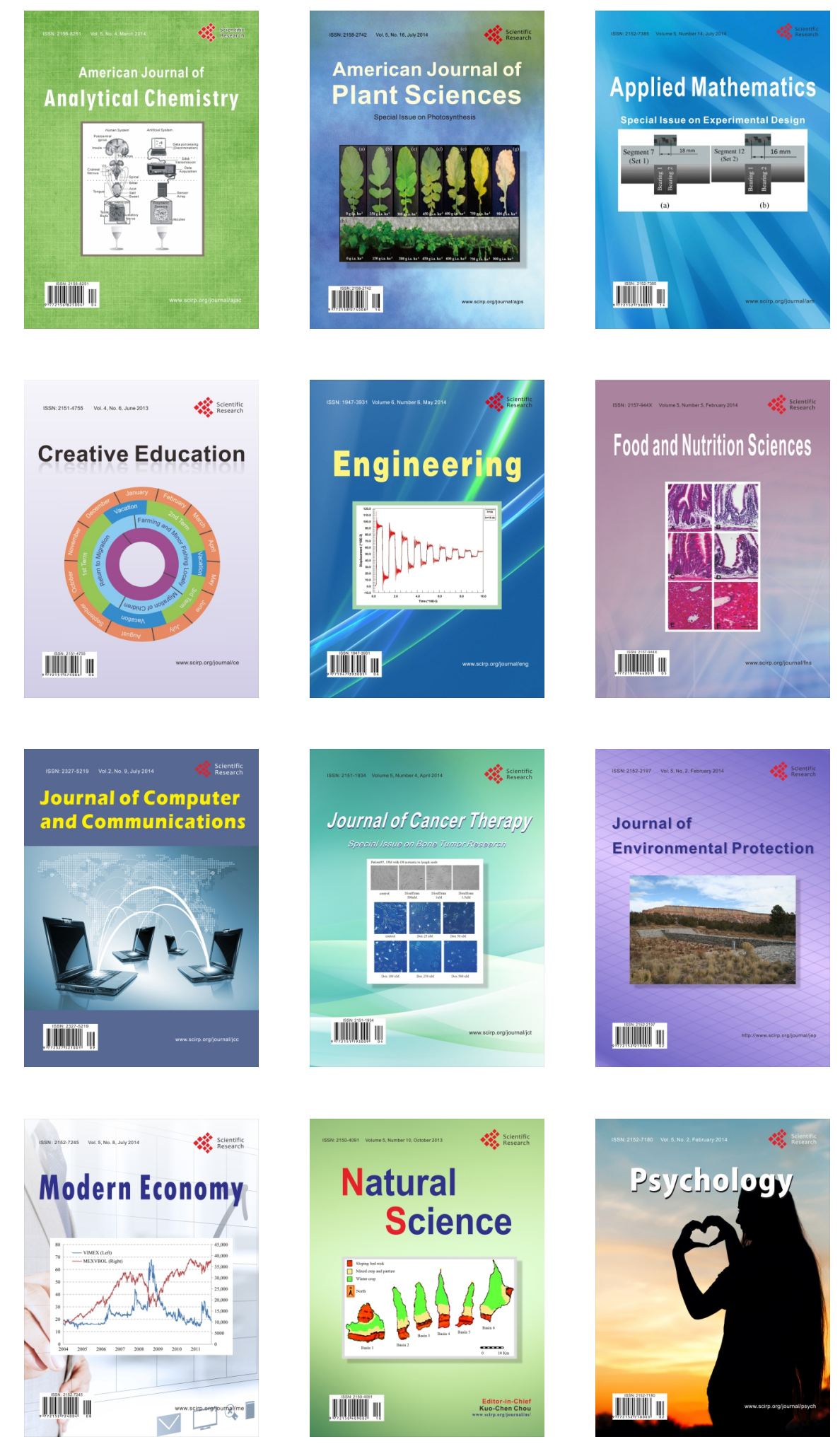